\title{
PERAN DEBT TO EQUITY RATIO DALAM MEMEDIASI PENGARUH CURRENT RATIO DAN INSTITUTIONAL OWNERSHIP TERHADAP DIVIDEND PAYOUT RATIO PADA PERUSAHAAN MANUFAKTUR
}

\author{
Ika Rosyada Fitriati ${ }^{1}$, Nungki Pradita ${ }^{2}$ \\ Universitas Stikubank (UNISBANK) Semarang \\ Email korespondensi: $\underline{\text { ikarosyada@edu.unisbank.ac.id }}{ }^{1}$
}

\begin{abstract}
This study aims to examine the effect of current ratio variables and institutional ownership on dividend payout ratio and the role of debt to equity ratio in mediating those effects. The sampling method that is used in the study is purposive sampling method. This study uses financial statement data published in Indonesian Capital Market Directory (ICMD). The feasibility test of the model was tasted using a multicollinearity test, test the coefficient of determination and significance test. Path analysis and sobel test are used in hypothesis testing. The result of the study found that the current ratio has a significant negative effect on the debt to equity ratio, the debt to equity ratio has a significant negative effect on the dividend payout ratio and the debt to equity ratio is able to mediate the effect of the current ratio on the dividend payout ratio.
\end{abstract}

Keywords: current ratio, institutional ownership, debt to equity ratio and dividend payout ratio

\section{A. PENDAHULUAN}

Investasi merupakan suatu upaya yang dilakukan untuk mengamankan kekayaan dan memperoleh keuntungan di masa yang akan datang. Investasi dapat dilakukan oleh individu maupun institusi. Salah satu bentuk investasi yang banyak diminati investor individu adalah investasi pada pasar modal. Investasi pada pasar modal berkembang pesat karena faktor kemudahan transaksi, keterbukaan informasi dan besarnya keuntungan yang ditawarkan. Keuntungan dalam investasi pada pasar modal dapat berupa dividen dan capital gain. Kebijakan dividen perusahaan dapat dilihat dari besarnya dividend payout ratio. Dividend payout ratio menentukan porsi keuntungan yang akan dibagi kepada pemegang saham dan yang akan ditahan sebagai modal operasi perusahaan pada periode selanjutnya.

Keuntungan yang diterima investor pasar modal sangat dipengaruhi dengan kebijakan dividen perusahaan, sehingga penting bagi investor untuk mengetahui faktor-faktor apa saja yang memengaruhi kebijakan tersebut. Kebijakan dividen diambil dengan mempertimbangkan faktor internal perusahaan maupun faktor eksternal. Likuiditas, kepemilikan institusi dan kebijakan hutang merupakan contoh dari faktor internal suatu perusahaan.

Current ratio merupakan salah satu rasio likuiditas yang mengukur seberapa jauh aktiva lancar perusahaan dapat dipakai untuk memenuhi kewajiban lancarnya. Current ratio perlu dikelola dengan optimal agar dapat menghasilkan keuntungan yang maksimal. Penelitian 
Mehta (2012) menemukan hasil likuiditas merupakan penentu dari kebijakan dividen perusahaan. Perusahaan dengan likuiditas tinggi memiliki kemampuan dalam pembayaran dividen secara tunai (cash dividend). Hal ini didukung oleh hasil penelitian Wasike \& Ambrose (2015) dan Ahmed (2015) yang menemukan bahwa current ratio berpengaruh positif signifikan terhadap dividend payout ratio. Namun, hasil berbeda ditemukan oleh Tariq (2015) yang menyatakan bahwa current ratio berpengaruh negatif signifikan terhadap dividend payout ratio. Nerviana (2015) dan Deitiana (2013) menemukan bahwa current ratio tidak memengaruhi dividend payout ratio.

Institutional ownership atau kepemilikan institusi diartikan sebagai porsi kepemilikan saham suatu perusahaan oleh pihak institusi misalnya pemerintah atau perusahaan lain. Institusi sebagai pemegang saham mempunyai pengaruh yang lebih besar jika dibandingkan dengan pemegang saham individu termasuk dalam hal mengendalikan dan mengawasi kebijakan manajemen perusahaan. Penelitian Betania (2015) menemukan semakin besar porsi saham yang dimiliki oleh institusi akan meningkatkan besarnya dividen yang dibagi. Pihak institusi mampu memengaruhi manajemen dalam menentukan kebijakan dividen. Pada dasarnya investor lebih menyukai dividen yang dibagikan secara tunai. Penelitian Moradi, Aldin, Forough Heyrani, \& Iranmahd (2012) menemukan pengaruh positif signifikan dari institutional ownership terhadap dividend payout ratio. Hasil penelitian yang berbeda ditemukan oleh AlNajjar (2016) serta Putri \& Nasir (2006) yang menyatakan institutional ownership berpengaruh negatif signifikan terhadap dividend payout ratio. Sedangkan menurut Wardhana (2013), institutional ownership tidak berpengaruh terhadap dividend payout ratio.

Modal perusahaan dalam menjalankan operasionalnya dapat bersumber dari ekuitas dan hutang. Salah satu fungsi manajemen keuangan dalam perusahaan adalah menetapkan kebijakan pendanaan seperti kebijakan hutang. Kebijakan hutang perusahaan terlihat dari rasio hutang (debt to equity ratio). Kebijakan hutang perusahaan dapat memengaruhi kebijakan dividen, hutang perusahaan yang tinggi mengakibatkan kemampuan membayar dividen semakin kecil, hal ini disebabkan berkurangnya keuntungan perusahaan karena adanya biaya hutang (Al-Najjar, 2016). Penelitian Al-Najjar (2016) menunjukkan hasil bahwa terdapat pengaruh negatif signifikan debt to equity ratio terhadap dividend payout ratio. Hasil serupa ditemukan oleh Nerviana (2015), debt to equity ratio yang tinggi secara signifikan dapat menurunkan dividend payout ratio. Hasil sebaliknya ditemukan oleh Moradi et al. (2012) yang menyatakan bahwa debt to equity ratio berpengaruh positif signifikan terhadap dividend payout ratio. Penelitian yang dilakukan oleh Putri \& Nasir (2006) memperoleh hasil tidak terdapat pengaruh signifikan debt to equity ratio terhadap dividend payout ratio. 
Kebijakan hutang dapat juga dipengaruhi faktor internal perusahaan. Likuiditas dan kepemilikan institusi diduga mampu memengaruhi kebijakan hutang yang akhirnya berpengaruh terhadap kebijakan dividen. Perusahaan dengan current ratio yang tinggi memiliki kemampuan untuk memenuhi kewajiban atas hutang lancarnya. Likuiditas perusahaan yang tinggi akan memberi kesempatan perusahaan untuk mengelola aset lancarnya sehingga kebutuhan terhadap hutang akan menurun dan mengakibatkan rasio hutang terhadap modal perusahaan semakin kecil. Penelitian Masnoon \& Saeed (2014), Jahanzeb \& Bajuri (2014) serta Šarlija \& Harc (2012) menemukan pengaruh negatif signifikan current ratio terhadap debt to equity ratio. Hasil yang berbeda ditemukan penelitian Gharaibeh (2015) yaitu perubahan posisi likuiditas suatu perusahaan berpengaruh positif signifikan terhadap perubahan rasio hutang.

Institutional ownership yang tinggi mencerminkan bahwa porsi saham yang dimiliki institusi relatif besar. Pemilik institusi berkesempatan mengendalikan serta mengawasi kebijakan manajemen perusahaan termasuk kebijakan hutang. Hal ini dapat terjadi karena pemilik institusi menguasai sebagian besar saham perusahaan sehingga memiliki pengaruh lebih dominan jika dibanding pemegang saham individu. Betania (2015) menyatakan bahwa semakin besar kepemilikan saham oleh institusi dapat memperkecil debt to equity ratio sehingga dapat dikatakan terdapat pengaruh negatif signifikan institutional ownership terhadap debt toquity ratio. Kepemilikan institusi yang semakin besar dapat memperkecil rasio hutang karena peran pemilik saham institusi dalam mengawasi kinerja manajemen perusahaan relatif kuat dan ketat. Penelitian Tariq (2015) juga menemukan pengaruh negatif institutional ownership terhadap debt to equity ratio. Hasil penelitian berbeda ditemukan oleh Moradi et al. (2012) yang menemukan pengaruh positif institutional ownership terhadap debt to equity ratio sedangkan Putri \& Nasir (2006) menemukan bahwa secara statistik kepemilikan institusional tidak berpengaruh secara signifikan terhadap kebijakan modal.

Selama periode pengamatan sejak tahun 2012-2014, dari laporan keuangan perusahaan manufaktur yang terdaftar pada Bursa Efek Indonesia dapat diketahui bahwa perubahan nilai pembayaran dividen, struktur modal, likuiditas dan kepemilikan institusi tidak seragam. Hal ini menunjukkan adanya fenomena gap pada perusahaan manufaktur di Indonesia. Penelitian terdahulu mengenai pengaruh variabel current ratio dan institutional ownership terhadap debt to equity ratio dan dampaknya terhadap dividend payout ratio menunjukkan hasil yang berbeda dan tidak konsisten sehingga terjadi research gap. Fenomena gap dan research gap tersebut menjadi alasan untuk melakukkan penelitian lebih lanjut mengenai faktor-faktor yang memengaruhi dividend payout ratio. Penelitian ini dilakukan untuk mengetahui peran debt to 
equity ratio dalam memediasi pengaruh current ratio dan institutional ownership terhadap dividend payout ratio.

Tabel 1. Rata-rata Dividend Payout Ratio, Debt to Equity Ratio, Current Ratio dan Institutional Ownership Perusahaan Manufaktur yang Terdaftar pada Bursa Efek Indonesia Periode 2012 sampai dengan 2014

\begin{tabular}{|l|c|c|c|}
\hline \multirow{2}{*}{ Variabel } & \multicolumn{3}{c|}{ Tahun } \\
\cline { 2 - 4 } & $\mathbf{2 0 1 4}$ & $\mathbf{2 0 1 3}$ & $\mathbf{2 0 1 2}$ \\
\hline Dividend payout ratio & $32,45 \%$ & $27,32 \%$ & $23,60 \%$ \\
\hline Debt to equity ratio & $0,87 \mathrm{x}$ & $0,80 \mathrm{x}$ & $0,89 \mathrm{x}$ \\
\hline Current ratio & $2,11 \mathrm{x}$ & $2,28 \mathrm{x}$ & $2,38 \mathrm{x}$ \\
\hline Institutional ownership & $64,64 \%$ & $64,37 \%$ & $66,11 \%$ \\
\hline
\end{tabular}

Sumber: Laporan keuangan pada ICMD 2015

\section{B. TELAAH PUSTAKA}

\section{Pengaruh Current Ratio terhadap Debt to Equity Ratio}

Likuiditas diartikan sebagai kemampuan perusahaan untuk memenuhi kewajiban jangka pendeknya. Jika perusahaan memiliki likuiditas yang tinggi, manajemen cenderung akan mengurangi proporsi hutangnya. Current ratio merupakan salah satu rasio yang sering digunakan untuk menilai likuiditas perusahaan. Current ratio menunjukkan perbandingan antara aktiva lancar dengan kewajiban lancar perusahaan. Penelitian terdahulu yang dilakukan oleh Šarlija \& Harc (2012); Jamal et al. (2013) serta Jahanzeb \& Bajuri (2014) menemukan bahwa secara signifikan likuiditas berpengaruh negatif terhadap leverage perusahaan.

$H_{1} \quad$ : Current ratio berpengaruh negatif signifikan terhadap debt to equity ratio

\section{Pengaruh Instututional Ownership terhadap Debt to Equity Ratio}

Institutional ownership atau kepemilikan institusi merupakan persentase jumlah saham perusahaan yang dimiliki oleh institusi. Institutional ownership yang tinggi membuat pengawasan pemegang saham terhadap manajer semakin ketat, salah satunya dalam hal kebijakan pendanaan. Pemegang saham cenderung tidak menyukai penggunaan hutang yang berlebihan karena semakin tinggi porsi hutang akan meningkatkan beban bunga yang mengakibatkan turunnya laba bersih dan mengurangi jumlah dividen yang dapat dibagikan. Penelitian terdahulu yang dilakukan oleh Al-Najjar (2010); Tariq (2015) dan Betania (2015) 
menemukan bahwa secara signifikan institutional ownership berpengaruh negatif terhadap debt to equity ratio.

$\mathrm{H}_{2}$ : Institutional ownership berpengaruh negatif signifikan terhadap debt to equity ratio

\section{Pengaruh Current Ratio terhadap Dividend Payout Ratio}

Perusahaan yang memiliki likuiditas tinggi cenderung memiliki kemampuan membayar dividen yang lebih tinggi dibanding perusahaan yang memiliki likuiditas rendah. Likuiditas merupakan faktor yang perlu diperhatikan dalam penentuan kebijakan dividen (Wasike \& Ambrose, 2015). Likuiditas yang tinggi mendorong perusahaan untuk meningkatkan proporsi dividen yang dibagikan secara tunai karena pada dasarnya pemegang saham cenderung menyukai dividen yang dibagikan secara tunai sebagai mana yang dinyatakan dalam the bird in the hand theory. Penelitian terdahulu yang dilakukan oleh Mehta (2012) dan Ahmed (2015) menemukan bahwa likuiditas secara signifikan berpengaruh terhadap dividend payout ratio.

$\mathrm{H}_{3}$ : Current ratio berpengaruh positif signifikan terhadap dividend payout ratio

\section{Pengaruh Institutional Ownership terhadap Dividend Payout Ratio}

Pemegang saham institusi cenderung memiliki porsi kepemilikan yang lebih besar dibandingkan pemegang saham individu. Penelitian yang dilakukan oleh Putri \& Nasir (2006) menemukan bahwa sesuai dengan agency theory, perusahaan dengan institutional ownership tinggi akan melakukan monitoring agents dengan tujuan porsi dividen yang dibagi lebih besar. Hasil penelitian Al-Nawaiseh (2013) menunjukkan bahwa institutional ownership secara signifikan berpengaruh positif terhadap dividend payout ratio.

$H_{4} \quad$ : Institutional ownership berpengaruh positif signifikan terhadap dividend payout ratio

\section{Pengaruh Debt to Equity Ratio terhadap Dividend Payout Ratio}

Kebijakan pendanaan perusahaan tercermin dari debt to equity ratio yang merupakan perbandingan antara dana yang bersumber dari hutang (debt) dan dana yang bersumber dari modal sendiri (equity). Porsi hutang yang semakin tinggi akan meningkatkan beban hutang, salah satunya adalah beban bunga. Hal ini dapat mengurangi kemampuan perusahaan dalam membayar dividen kepada pemegang saham. Penelitian terdahulu yang dilakukan oleh Moradi et al. (2012); Nerviana (2015) dan Betania (2015) menemukan bahwa debt to equity ratio secara signifikan berpengaruh negatif terhadap dividend payout ratio.

$H_{5}$ : Debt to equity ratio berpengaruh negatif signifikan terhadap dividend payout ratio 
Peran Debt to Equity Ratio dalam Memediasi Pengaruh Current Ratio terhadap Dividend

\section{Payout Ratio}

Likuiditas yang tinggi berpotensi digunakan untuk membayar kewajiban atau hutang perusahaan sehingga dapat menurunkan debt to equity ratio. Porsi hutang yang semakin menurun dapat mengurangi beban bunga perusahaan sehingga meningkatkan kemampuan perusahaan dalam membayar dividen tunai kepada pemegang saham. Kebijakan dividen juga dapat dipengaruhi oleh tinggi rendahnya likuiditas. Perusahaan dengan likuiditas yang tinggi cenderung memiliki kemampuan membayar dividen yang lebih baik. Penelitian yang dilakukan oleh Tariq (2015) menemukan bahwa secara signifikan likuiditas perusahaan mampu memengaruhi kebijakan pendanaan dan kebijakan dividen, current ratio berpengaruh negatif terhadap debt to equity ratio dan berpengaruh positif terhadap dividend payout ratio.

$H_{6}$ : debt to equity ratio mampu memediasi pengaruh current ratio terhadap dividend payout ratio

\section{Peran Debt to Equity Ratio dalam Memediasi Pengaruh Institutional Ownership terhadap}

\section{Dividend Payout Ratio}

Pemegang saham cenderung tidak menyukai penggunaan dana yang bersumber dari hutang karena dapat menurunkan dividen yang dibagikan (Jensen, 2012). Pemegang saham institusi memiliki potensi memengaruhi kebijakan manajerial karena pada umumnya porsi saham yang dimiliki relatif besar. Sejalan dengan agency theory, institutional ownership yang tinggi berpotensi lebih besar dalam menjalankan monitoring agents dengan baik. Hal ini dapat membatasi kebijakan manajer dalam penggunaan hutang sehingga diharapkan dapat meningkatkan porsi dividen yang dibagikan. Penelitian terdahulu yang dilakukan oleh Putri \& Nasir (2006); Wardhana (2013) serta Betania (2015) menemukan bahwa debt to equity ratio mampu memediasi pengaruh institutional ownership terhadap dividend payout ratio.

$H_{7}$ : debt to equity ratio mampu memediasi pengaruh institutional ownership terhadap dividend payout ratio

\section{Kerangka Pemikiran Teoritis}

Kerangka pemikiran teoritis yang disusun bedasarkan uraian telaah pustaka dan pengembangan hipotesis di atas adalah sebagai berikut: 


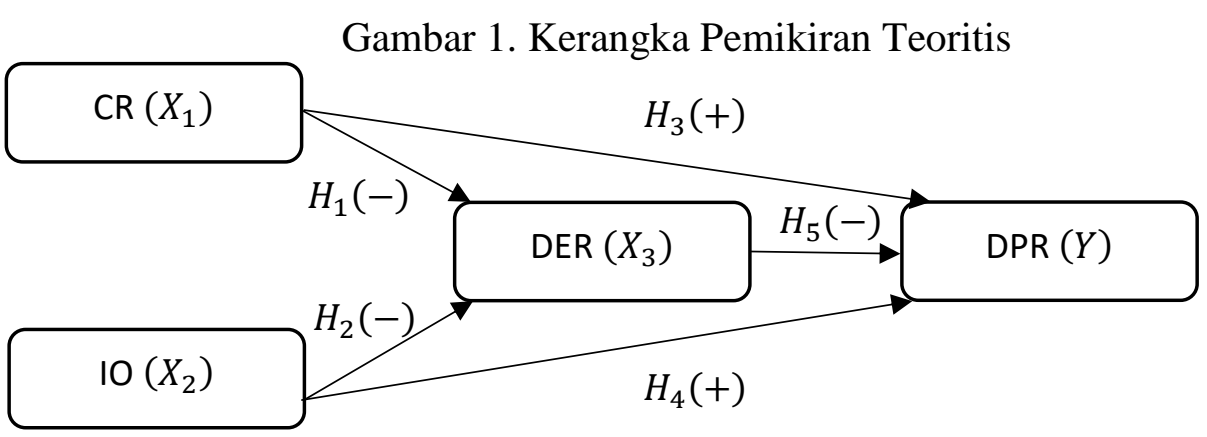

Sumber : Jahanzeb \& Bajuri (2014); Tariq (2015); Mehta (2012); Ahmed (2015); Moradi et al. (2012) yang diolah dan disesuaikan untuk keperluan penelitian.

\section{METODOLOGI PENELITIAN}

\section{Jenis dan Variabel Penelitian}

Penelitian dilakukan untuk menguji dan menganalisis faktor-faktor yang mempengaruhi keputusan dividen. Data yang digunakan dalam penelitian ini adalah data tahunan dividend payout ratio, debt to equity ratio, current ratio serta institutional ownership. Periode pengamatan dilakukan dari tahun 2012 hingga 2014. Data dalam penelitian ini bersumber dari ICMD 2015 yang kemudian disalin untuk diolah dan dianalisis. Pemilihan periode pengamatan tersebut didasari alasan kelengkapan data, karena untuk tahun-tahun berikutnya masih banyak data yang not available (n.a.).

Variabel yang digunakan dalam penelitian ini terdiri dari variabel dependen yaitu dividend payout ratio (DPR), variabel intervening yaitu debt to equity ratio (DER) serta variabel independen yang terdiri dari current ratio (CR) dan institutional ownership (IO). Adapun definisi operasional dari masing-masing variabel adalah:

- Dividend payout ratio (DPR) didefinisikan sebagai perbandingan atau rasio antara dividend per share dengan earning per share. Dividend payout ratio dapat dirumuskan sebagai berikut (Ang, 1997):

$$
D P R=\frac{\text { Dividend per share }}{\text { Earning per share }} \times 100 \%
$$

- Debt to equity ratio (DER) didefinisikan sebagai perbandingan atau rasio antara total hutang dengan total hutang dengan total ekuitas. Debt to equity ratio dapat dirumuskan sebagai berikut (Ang, 1997):

$$
D E R=\frac{\text { Total debts }}{\text { Total shareholders equity }}
$$

- Current ratio (CR) didefinisikan sebagai perbandingan atau rasio antara total hutang dengan hutang lancar. Current ratio dapat dirumuskan sebagai (Ang, 1997): 


$$
C R=\frac{\text { Current assets }}{\text { Current liabilities }}
$$

- Institutional ownership (IO) didefinisikan sebagai jumlah saham yang dimiliki oleh institusi. Institutional ownership dapat dirumuskan sebagai (Tariq, 2015):

$$
I O=\frac{\text { Total saham institusi }}{\text { Total saham yang beredar }}
$$

\section{Metode Analisis}

Metode analisis yang digunakan dalam penelitian ini adalah metode analisis regresi berganda dan kemudian dikembangkan lebih lanjut menjadi model analisis jalur. Keterbatasan jumlah sampel penelitian menjadi alasan penelitian ini menggunakan pendekatan Partial Least Squares (PLS). Pendekatan PLS adalah ditribution free (Ghozali, 2014). Uji multikolinieritas, uji koefisien determinansi serta uji signifikansi dalam penelitian ini digunakan sebagai indikator penilaian goodness of fit model.

\section{HASIL DAN PEMBAHASAN}

\section{Hasil Uji Multikolinieritas}

Sebelum melakukan analisis hipotesis, dalam penelitian ini dilakukan uji multikolinieritas yang bertujuan untuk memeriksa apakah dalam model persamaan regresi terdapat korelasi yang kuat antar variabel independen. Jika terdapat gejala multikolinieritas pada model persamaan regresi, maka akan menimbulkan ketidakpastian estimasi yang mengarahkan kesimpulan menerima hipotesis nol (Ghozali, 2014). Uji multikolinieritas dalam penelitian ini dilakukan dengan perhitungan nilai variance inflation factor (VIF). Hasil dari uji multikolinieritas dapat dilihat dari Tabel 2 berikut :

Tabel 2. Hasil Uji Multikolinieritas

\begin{tabular}{|c|c|c|}
\hline Variabel Independent & \multicolumn{2}{|c|}{ Variance Inflation Factor (VIF) } \\
\cline { 2 - 3 } & DER & DPR \\
\hline CR & 1,019 & 1,247 \\
\hline IO & 1,019 & 1,020 \\
\hline DER & & 1,233 \\
\hline
\end{tabular}

Sumber : Hasil output Smart PLS, data diolah 2019

Hasil uji multikolinieritas menunjukkan bahwa semua variabel independen dari model yang diteliti tidak terdapat multikolinieritas yang ditunjukkan oleh nilai VIF yang jauh dibawah 10. Hasil ini menunjukkan bahwa model dalam penelitian ini layak untuk digunakan dan model dinyatakan memenuhi syarat untuk diteliti. 


\section{Hasil Uji Koefisien Determinasi}

Dalam penelitian ini dilakukan uji koefisien determinasi $\left(R^{2}\right)$ guna menilai sejauh mana model mampu menjelaskan variasi variabel dependen. Dalam buku Ghozali (2014) dijelaskan bahwa nilai $\left(R^{2}\right)$ yang mendekati satu menunjukkan bahwa hampir semua informasi yang diperlukan untuk memrediksi variabel dependen telah diberikan oleh variabel-variabel independen dalam model. Sedangkan nilai $\left(R^{2}\right)$ yang mendekati nol menunjukkan keterbatasan kemampuan variabel-variabel independen dalam menjelaskan variasi variabel dependen. Nilai koefisien determinansi dari penelitian ini disajikan dalam Tabel 3 sebagai berikut :

Tabel 3. Koefisien Determinansi

\begin{tabular}{|c|c|c|}
\hline Dependent Variable & R Square & Adjuusted R Square \\
\hline DER & 0,189 & 0,163 \\
\hline DPR & 0,249 & 0,212 \\
\hline
\end{tabular}

Sumber : Hasil output Smart PLS, data diolah 2019

Nilai adjusted $R$ square sebesar 0,163 untuk variabel dependen DER menunjukkan bahwa variasi variabel independen mampu menjelaskan 16,3\% variasi variabel dependen, sedangkan sisanya sebesar $83,7 \%$ dijelaskan oleh variabel lain di luar variabel independen. Nilai adjusted $R$ square sebesar 0,212 untuk variabel dependen DPR menunjukkan bahwa variasi variabel independen mampu menjelaskan $21,2 \%$ variasi variabel dependen, sedangkan sisanya sebesar 78,8\% dijelaskan oleh variabel lain di luar variabel independen.

\section{Hasil Uji Signifikansi (Uji t)}

Uji statistik t pada dasarnya menunjukkan seberapa jauh pengaruh satu variabel penjelas/independen secara individual dalam menerangkan variasi variabel dependen. Nilai $\mathrm{t}$ statistik akan dibandingkan dengan nilai t tabel pada tingkat signifikansi tertentu. Nilai $t$ statistik harus lebih besar daripada t tabel. Penelitian ini menggunakan tingkat signifikansi 5\% sehingga t statistik harus lebih besar dari 1,967. Hasil uji t disajikan dalam Tabel 4 sebagai berikut :

Tabel 4. Uji t

\begin{tabular}{|l|c|c|c|c|c|}
\hline Variable & Coefficient & Sample Mean & Standard Error & T Statistics & P Value \\
\hline DER & 0,189 & 0,209 & 0,059 & 3,224 & 0,001 \\
\hline DPR & 0,249 & 0,279 & 0,082 & 3,040 & 0,002 \\
\hline
\end{tabular}

Sumber: Hasil output SmartPLS, data diolah 2019 
Dari Tabel 4 terlihat bahwa semua variabel memiliki t hitung yang lebih besar dari t tabel $(1,967)$ dan tingkat signifikansi yang lebih kecil dari 0,05. Hal ini menunjukkan bahwa kedua model regresi dapat dinyatakan layak diteliti.

\section{Hasil Analisis Jalur}

Analisis jalur (path analysis) dilakukan menggunakan software SmartPLS yang hasilnya disajikan dalam Tabel 5 berikut:

Tabel 5. Path Coefficients (Mean, Std Error, T Statistics dan P Value)

\begin{tabular}{|c|c|c|c|c|c|}
\hline Variable Effect & Coefficient & Sample Mean & Standart Error & T Statistics & P Value \\
\hline CR > DER & $-0,430$ & $-0,431$ & 0,076 & 5,663 & 0,000 \\
\hline IO > DER & $-0,026$ & $-0,030$ & 0,122 & 0,212 & 0,832 \\
\hline CR > DPR & 0,224 & 0,223 & 0,147 & 1,524 & 0,128 \\
\hline IO > DPR & 0,017 & 0,011 & 0,098 & 0,174 & 0,862 \\
\hline DER > DPR & $-0,356$ & $-0,356$ & 0,093 & 3,816 & 0,000 \\
\hline
\end{tabular}

Sumber : Hasil output Smart PLS, data diolah 2019

Penelitian ini menggunakan analisis regresi berganda yang kemudian dikembangkan lebih lanjut menjadi model analisis jalur. Persamaan regresi yang dapat disusun berdasarkan Tabel 5 untuk penelitian ini adalah sebagai berikut :

$$
\begin{aligned}
& D E R=-0,430 C R-0,026 I O \\
& D P R=0,224 C R+0,017 I O-0,356 D E R
\end{aligned}
$$

Mediasi variabel intervening pada pengaruh variabel independen terhadap variabel dependen dapat digambarkan sebagai berikut :

\section{Gambar 2. Analisi Jalur}

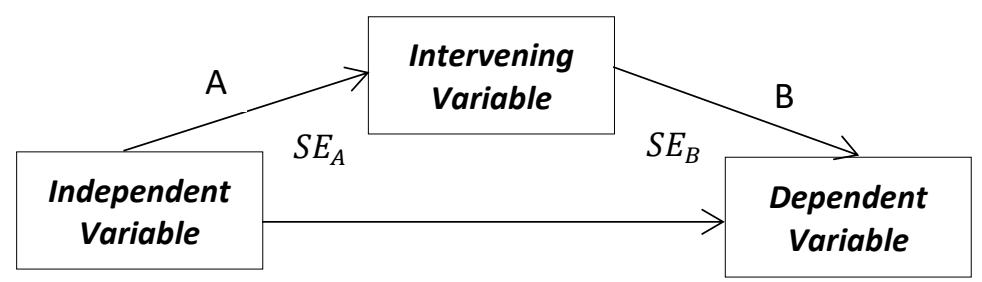

Sumber : Ghozali (2014)

Pengujian mediasi dilakukan dengan menggunakan sobel test dan diperoleh hasil sebagai berikut : 
Tabel 6. Sobel Test

\begin{tabular}{|c|c|c|c|c|r|}
\hline PENGARUH VARIABEL & $\mathbf{A}$ & $\mathbf{B}$ & $\boldsymbol{S E}_{\boldsymbol{A}}$ & $\boldsymbol{S E}_{\boldsymbol{B}}$ & $\boldsymbol{t}_{\text {statistics }}$ \\
\hline CR terhadap DPR melalui DER & $-0,430$ & $-0,356$ & 0,076 & 0,093 & 3,170 \\
\hline IO terhadap DPR melalui DER & $-0,026$ & $-0,356$ & 0,122 & 0,093 & 0,213 \\
\hline
\end{tabular}

Sumber : Hasil output Sobel Test, data diolah 2019

Hasil pengujian dengan menggunakan sobel test pada Tabel 6. terlihat t hitung untuk pengaruh variabel CR terhadap DPR melalui DER sebesar 3,170 lebih besar dari t tabel (1,967), hal ini menunjukkan bahwa variabel debt to equity ratio berperan memediasi pengaruh variabel current ratio terhadap dividend payout ratio. Sedangkan untuk pengaruh variabel IO terhadap DPR melalui DER sebesar 0,213 lebih kecil dari t tabel $(1,967)$, hal ini menunjukkan bahwa variabel debt to equity ratio tidak berperan memediasi pengaruh variabel institutional ownership terhadap dividend payout ratio.

\section{Pembahasan}

Berdasarkan hasil pengujian pada Tabel 5 dapat dinyatakan terdapat pengaruh negatif signifikan dari current ratio terhadap debt to equity ratio. Hasil penelitian konsisten dengan pecking order theory yang menyatakan bahwa perusahaan memprioritaskan penggunaan ekuitas untuk membiayai operasional perusahaan sehingga ketika terdapat kelebihan likuiditas, maka perusahaan akan mengurangi proporsi hutangnya. Hasil pengujian sejalan dengan penelitian yang dilakukan oleh Šarlija \& Harc (2012); Jahanzeb \& Bajuri (2014); serta Masnoon \& Saeed (2014). Secara umum dapat dinyatakan, hipotesis pertama dalam penelitian ini diterima.

Hasil pengujian pada Tabel 5 menunjukkan institutional ownership tidak memiliki pengaruh terhadap debt to equity ratio. Besar kecilnya porsi saham yang dimiliki investor institusi tidak memengaruhi kebijakan pendanaan perusahaan. Penelitian ini tidak sejalan dengan hasil penelitian Al-Najjar (2010); Betania (2015) serta Tariq (2015) yang menemukan bahwa institutional ownership memiliki pengaruh negatif signifikan terhadap debt to equity ratio. Secara umum dapat dinyatakan, hipotesis kedua dalam penelitian ini ditolak.

Hasil pengujian pada Tabel 5 menunjukkan current ratio tidak memiliki pengaruh terhadap dividend payout ratio. Likuiditas perusahaan yang meningkat tidak dapat secara langsung memengaruhi kebijakan dividen perusahaan. Penelitian ini tidak sejalan dengan hasil penelitian Mehta (2012); Ahmed (2015) serta Wasike \& Ambrose (2015). Secara umum dapat dinyatakan, hipotesis ketiga dalam penelitian ini ditolak. 
Hasil pengujian pada Tabel 5 menunjukkan institutional ownership tidak memiliki pengaruh terhadap dividend payout ratio. Kebijakan dividen perusahaan tidak bergantung pada proporsi kepemilikan saham oleh institusi. Pemilik saham institusi tidak serta merta dapat menjalankan monitoring agents dengan maksimal guna meningkatkan pembagian dividen. Hasil pengujian tidak konsisten dengan agency theory yang menyatakan bahwa setiap individu cenderung untuk memaksimalkan utilitasnya. Hasil tersebut juga tidak sejalan dengan hasil penelitian Putri \& Nasir (2006) serta Al-Nawaiseh (2013). Secara umum dapat dinyatakan, hipotesis keempat dalam penelitian ini ditolak.

Hasil pengujian pada Tabel 5 menunjukkan debt to equity ratio berpengaruh negatif signifikan terhadap dividend payout ratio. Debt to equity ratio yang semakin rendah berpengaruh pada meningkatnya dividend payout ratio. Rendahnya biaya hutang dapat meningkatkan kemampuan perusahaan untuk membayar dividen. Hal ini konsisten dengan balancing theory serta hasil penelitian Nerviana (2015); Betania (2015) serta Al-Najjar (2016). Secara umum dapat dinyatakan, hipotesis kelima dalam penelitian ini diterima.

Hasil pengujian sobel test pada Tabel 6 menunjukkan bahwa variabel debt to equity ratio berperan sebagai mediator pengaruh variabel current ratio terhadap variabel dividend payout ratio. Jika perusahaan memiliki likuiditas yang tinggi, perusahaan cenderung mengurangi proporsi hutangnya sehingga beban hutang atau bunga perusahaan akan menurun yang menyebabkan kemampuan perusahaan dalam pembayaran dividen semakin meningkat sehingga berpotensi meningkatkan dividend payout ratio. Berdasarkan hasil pengujian tersebut dapat dinyatakan hipotesis keenam dalam penelitian ini diterima.

Hasil pengujian sobel test pada Tabel 6 menunjukkan bahwa variabel debt to equity ratio tidak berperan sebagai mediator pengarih variabel institutional ownership terhadap variabel dividend payout ratio. Perubahan proporsi hutang perusahaan tidak dapat memediasi pengaruh institutional ownership terhadap dividend payout ratio. Institutional ownership secara langsung maupun melalui debt to equity ratio tidak berpengaruh secara signifikan terhadap dividend payout ratio. Besarnya proporsi kepemilikan saham perusahaan oleh institusi tidak dapat meningkatkan rasio pembayaran dividen. Berdasarkan hasil pengujian tersebut dapat dinyatakan hipotesis ketujuh dalam penelitian ini ditolak.

\section{E. KESIMPULAN}

\section{Kesimpulan}

Dividend payout ratio dapat ditingkatkan dengan cara menurunkan besarnya debt to equity ratio. Hal ini disebabkan karena debt to equity ratio berpengaruh negatif signifikan 
terhadap dividend payout ratio. Debt to equity ratio dapat diturunkan dengan cara meningkatkan besarnya current ratio karena current ratio berpengaruh negatif signifikan terhadap debt to equity ratio. Debt to equity ratio sebagai variabel intervening mampu memediasi pengaruh current ratio terhadap dividend payout ratio. Debt to equity ratio yang menurun akibat peningkatan current ratio dapat berpengaruh pada meningkatnya dividend payout ratio perusahaan.

Penelitian ini masih terdapat beberapa keterbatasan antara lain, keterbatasan dalam jumlah sampel penelitian yaitu hanya 22 perusahaan manufaktur selama 3 tahun atau sebanyak 66 pengamatan. Keterbatasan sampel ini mengakibatkan model rawan tidak lolos uji asumsi klasik. Keterbatasan lain juga terlihat dari adjusted $\mathrm{R}$ square penelitian yang relatif kecil yaitu sebesar 0,163 pada model dengan variabel dependen debt to equity ratio dan 0,212 pada model dengan variabel dependen dividend payout ratio. Hal ini menunjukkan variabilitas konstruk variabel independen hanya mampu menjelaskan variabilitas konstruk debt to equity ratio sebesar $16,3 \%$ serta variabilitas konstruk dividend payout ratio sebesar 21,2\%, sehingga dapat dikatakan variabel independen lain yang memengaruhi variabel dependen lebih besar yaitu $83,7 \%$ untuk variabel yang menjelaskan debt to equity ratio dan $78,8 \%$ untuk variabel yang menjelaskan dividend payout ratio.

\section{Saran}

Bagi investor pasar modal hendaknya mengetahui faktor-faktor yang dapat meningkatkan dividend payout ratio. Dari hasil penelitian ini dapat disarankan bagi investor untuk memerhatikan current ratio dan debt to equity ratio suatu perusahaan. Investor hendaknya memilih perusahaan dengan current ratio yang tinggi dan debt to equity ratio yang rendah agar dapat memperoleh dividen yang tinggi.

Penelitian selanjutnya (future research) disarankan untuk memperluas objek yang diteliti yaitu seluruh perusahaan yang telah go-public. Penambahan periode tahun amatan perlu dilakukan agar perubahan masing-masing variabel setiap tahun sehingga diharapkan hasil penelitian menjadi lebih akurat. Penelitian selanjutnya juga disarankan untuk menambahkan variabel independen lain seperti profitabilitas, ukuran perusahaan, aliran kas bebas, aset berwujud atau variabel-variabel lain agar dapat meningkatkan nilai $\mathrm{R}$ square penelitian, sehingga dapat diperoleh model penelitian yang lebih fit atau variabel independen memiliki kemampuan yang lebih besar dalam menjelaskan variabel dependen.

\section{DAFTAR PUSTAKA}

Ahmed, I. E. (2015). Liquidity, Profitability and the Dividends Payout Policy, 5(2), 73-85. 
Al-Najjar, B. (2010). Corporate governance and institutional ownership: evidence from Jordan, 10(2), 176-190. https://doi.org/10.1108/14720701011035693

Al-Najjar, B. (2016). The Effect of Ownership Structure on Dividend Policy: Evidence from Turkey. The International Journal of Business in Society, 16(1).

Al-Nawaiseh, M. (2013). Dividend Policy and Ownership Structure : An Applied Study on Industrial Companies in Amman Stock Exchange. Journal of Management Research, 5(2), 83-106. https://doi.org/10.5296/jmr.v5i2.2920

Ang, R. (1997). Buku Pintar Pasar Modal Indonesia. Mediasoft Indonesia.

Betania, R. P. (2015). Pengaruh Insider Ownership, Asset Tangibility, Institutional Ownership dan Pertumbuhan Perusahaan terhadap Dividend Payout Ratio dengan Mediasi Debt to Equity Ratio. Universitas Diponegoro.

Deitiana, T. (2013). Pengaruh Current Ratio, Return on Equity dan Total Asset Turn Over terhadap Deviden Payout Ratio dan Implikasi pada Harga Saham, 15(1), 82-88.

Gharaibeh, A. M. O. (2015). The Determinants of Capital Structure: Empirical Evidence from Kuwait, 3(6), 1-25.

Ghozali, I. (2014). Structural Equation Modeling Metode Alternatif dengan Partial Least Squares (PLS) (4th ed.). Semarang: Badan Penerbit Universitas Diponegoro.

Jahanzeb, A., \& Bajuri, N. H. (2014). Determinants of Capital Structure: Empirical Evidence from Pakistan. SSRN Electronic Journal, 22(2), 272-278. https://doi.org/10.2139/ssrn.1977024

Jamal, A. A. A., Geetha, C., Mohidin, R., Abdul Karim, M. R., Sang, L. T., \& Ch'g, Y. (2013). Capital Structure Decisions : Evidence from Large Capitalized Companies in Malaysia. Interdisciplinary Journal of Contemporary Research in Business, 5(5), 30-49.

Jensen, M. C. (2012). Value Maximization, Stakeholder Theory, and the Corporate Objective Function. Business Ethics Quarterly, 12(2), 235-256.

Masnoon, M., \& Saeed, A. (2014). Capital Structure Determinants of Kse Listed Automobile Companies. European Scientific Journal, 10(13), 451-461.

Mehta, A. (2012). An Empirical Analysis of Determinants of Dividend Policy - Evidence from the UAE Companies Mehta. Global Reiew of Accounting and Finance, 3(1), 18-31.

Moradi, N. S., Aldin, M. M., Forough Heyrani, \& Iranmahd, M. (2012). The Effect of Corporate Governance, Corporate Financing Decision and Ownership Structure on Firm Performance: A Panel Data Approach from Tehran Stock Exchange. International Journal of Economics and Finance, 4(6), 86-93. https://doi.org/10.5539/ijef.v4n6p86

Nerviana, R. (2015). The Effect of Financial Ratios and Company Size on Dividend Policy. The Indonesian Accounting Review, 5(1), 23-32. https://doi.org/10.14414/tiar.15.050103

Putri, I. F., \& Nasir, M. (2006). Analisis Persamaan Simultan Kepemilikan Manajerial, Kepemilikan Institusional, Risiko, Kebijakan Hutang dan Kebijakan Dividen dalam Perspektif Teori Keagenan. Simposium Nasional Akuntansi 9 Padang, 23-26.

Šarlija, N., \& Harc, M. (2012). The Impact of Liquidity on the Capital Structure : A Case Study of Croatian Firms, 3(1), 30-36. https://doi.org/10.2478/v10305-012-0005-1 
Tariq, A. (2015). The Joint-Determinants of Leverage and Dividend Policy : a Balanced Panel Study of Non Financial Firms of India, 11(10), 311-328.

Wardhana, G. H. (2013). Pengaruh Profitability, Asset Tangibility dan Institutional Ownership terhadap Struktur Modal dan Dampaknya pada Kebijakan Dividen. Universitas Diponegoro.

Wasike, T. W., \& Ambrose, J. (2015). Determinants of Dividend Policy in Kenya. International Journal of Arts and Entrepreneurship, 4(11), 71-80. 